\title{
The level of destination management in the South-Moravian Region ${ }^{*}$
}

\author{
Katerina Ryglova, Ida Vajcnerova \\ (Department of Marketing and Trade, Faculty of Business and Economics, Mendel University in Brno, Brno 61300, Czech Republic)
}

\begin{abstract}
Tourism is not only a significant tool of prosperity in well-known tourist destinations, but it is also an important potential development element in developing rural regions. In Czech Republic, the field of regional development and managing destinations started to develop in the second half of the 1990s. Organizing tourism is in the phase of building and passes through natural development. Fierce competition between individual destinations imposes natural pressures on creating marketing managements of these destinations and such offer of products that perfectly come up to tourists' expectations. Together with increasing requirements, the demands on quality and well-prepared destinations within home tourism revive. In the final consequence, the level of destination management influences the increase in marketability and attendance in the region. The paper outlines the main theoretical basis, principles and tools of destination management, and subsequently it summarizes the results of the analysis, and conducted survey, the objective of which was to prove the functioning of these principles in practice. The practical verification of the functioning of destination management principles in Czech Republic has been conducted in the South-Moravian region (JMK) which is one of the most-often-visited regions in the country. The set targets have been reached not only by analysing available secondary data, but the techniques of depth interviews with experts in a destination management company have also been used, as well as the techniques of an orientation questionnaire survey among travel agencies and offices that should be one of the partners for a well-functioning destination management company.
\end{abstract}

Key words: destination management; tourism development; partnership; South-Moravian Region; destination management company

\section{Introduction and objective}

Destination management in Czech Republic is still in the initial stage of its development, and it is not yet developed in some west Europe countries. Although there is a common opinion that tourism represents a significant contribution to the life of regions, towns or villages, it was left to its fate in most cases even in the recent past and it was dependant solely on business activities of individual providers of tourism facilities.

The potential of tourism development in JMK and the basis on which a modern and competitive European destination can be created lies on the rustical character of a large part of the region, existing folk traditions,

\footnotetext{
* The results mentioned in this article are a part of the research project "Czech economy in the process of integration and globalization and the development of agrarian sector and service sector in new conditions of the European integrated market" ( id. code VZ: 62156 48904), that was realized with the financial support of public funds via The Ministry of Education-MŠMT.

Katerina Ryglova, Ph.D., associate professor, Department of Marketing and Trade, Mendel University in Brno; research fields: marketing of tourism, quality management in tourism.

Ida Vajcnerova, Ph.D., Department of Marketing and Trade, Mendel University in Brno; research fields: destination management, quality management in tourism.
} 
ecclesiastical sights, traditional rural and modern urban architecture, as well as the natural and country resources.

The objective of this paper is to describe the main theoretical basis and tools of destination management. Their concrete practical application is then analysed in one of the most frequented regions in Czech Republic, especially the South-Moravian region (JMK). The set targets were reached not only by analysing secondary available data but also by using the techniques of a depth interview with experts and an orientation questionnaire survey among travel agencies and offices, and the principal goal was to prove functioning of the basic principle of destination management, "3P”, i.e., effective cooperation between public and business sectors.

\section{Materials and methods}

In the monolingual dictionary of tourism, the term of destination is explained in the narrow sense of word as a target area in a given region, for which a significant offer of activities and tourism infrastructure are typical. In the broader sense, a destination is understood as countries, regions, human settlements and other areas that are typical with a high concentration of tourism attractions, developed services and other tourism infrastructure, the result of which is a long-term high concentration of visitors.

On the other hand, Királová (2004) defines a tourism destination as a natural whole which has unique features from the point of view of tourism development, and it is different from other destinations. Then, she refers to WTO statement according to a destination which represents a place with certain attractions and tourism facilities and services connected, which are chosen by a participant or a group of tourism for their visit and they are brought to the market by their providers. In her book, she refers to the work by Buhalis (2000) who defines six characteristic components marked as "six As" of each destination:

- Attractions-A primary offer of tourism that thanks to its amount, quality and attractiveness activates attendance (natural, cultural-historical potential);

- Accessibility and Ancillary services-A general infrastructure which enables the access to the destination, travelling to the attractions in the destination; also services are used mainly by local inhabitants, such as telecommunication, medical and banking services);

- Amenities - Superstructure and infrastructure of tourism that enable the stay in the destination and utilizing its attractions (accommodation, hostelry, sports-recreational, cultural-social facilities and others);

- Available packages-Prepared products and product packages;

- Activities-Various activities.

Bartl and Schmidt (1998) understand destination management as "the strategy and the way for strong regions which have the courage to concentrate their powers for collective development, organization and active sale of their key competitive advantages. In this way, destinations emerge which can offer their client a perfectly organized chain of services corresponding with his choice, and it includes the whole process from obtaining the information and comfortable reservation across flawless duration of his stay up to his coming back home" .

Hesková (2006) uses a different approach to consider the definition. She considers destination management to be the process of creating and managing strong, market oriented and system directed units-destinations. Thus, destination management is a set of controlling measures and tools that are used in the area of planning, organizing and promoting as well as in decision-making processes leading to the development of a destination. She also determines basic spheres of activities solved by destination management: 
- developing in compliance with permanent sustainability of the environment;

- setting economic targets;

- social-cultural sphere;

- internal and external communication.

For completeness, she adds that the management of destinations is a strategy of development that reacts to requirements of international global market, heads towards powerful units, strategical direction and competition. The author emphasizes the fact that a high level of cooperation among individual subjects participating in directing a destination is a considerable element in destination management.

The management of a destination can also be defined as "a system of managing skills and activities that are used during coordinated planning and organizing tourism in a certain destination". In other words, not only representatives of public sphere should be involved in the process of regional development strategic planning, but entrepreneurs, non-profit sector and civil initiatives should participate as well. In connection with this, we can often come across the term of "local self-government" that can be an unusual expression for many people. However, it is nothing but, as stated by Bernátová and Vaňová (2000), "attracting investors into the area, attracting tourists, communicating with the public or promoting the region". These are the main targets of the majority of public administration representatives. Thus, the marketing of an area (a place) is the marketing of local self-governments.

With respect to the highly competitive environment of tourism, individual destinations have to be managed and organized in a professional way. To ensure this function as well as many other ones, there exist so called destination agencies or destination management companies which are supported and financed by the strongest partners in the destination. According to Palatková (2006) the principal role of destination agencies lies on connecting relatively independent and legally autonomous service providers into one whole which acts cohesively as one and is directed at selling the key products of the destination. The goal of such a whole is then coordinating and cooperating, creating suitable chains of services and also creating "experiences" for target groups of clients while gaining the influence and control over individual partial services.

Destination management companies (DMC) should act in five main areas, as stated by Bartl, Schmidt (1998):

(1) the organization and coordination of vertical and horizontal connection of subjects with the aim to reach a unified, flexible and market-directed dynamic competitive unit;

(2) the critical comparison of the destination level with the best one of other destinations with the aim to reach a bigger benefit for a client, and at the same time, slimming necessary processes;

(3) the responsibility for fulfilling the basic functions of managing tourism in the destination; influencing service providers not as an "interest" organization but as a joint enterprise of service providers who finance it;

(4) fulfilling the function of offering;

(5) fulfilling the function of marketing.

Destination management companies are irreplaceable in their position of promoting the identity and image of the destination as a whole. The reason is that mostly none of private subjects can represent the country or region. The inability of market in creating resources needed by the marketing of the destination spontaneously is usually termed as a market failure. For the solution, three approaches are used:

- creating an own agency using the financial means of private subjects and selling the destination; 
- the intervention of the public sector, the result of which are publicly financed organizations, business subjects, local offices or other organizations taking responsibility for the marketing management of the destination;

- combining private and public ways of financing with the unambiguous trend of heading towards financing from private sources.

\section{Results}

The development of tourism in JMK is coordinated by the regional council- the section for tourism of the Department of Regional Development. In 2007, the office for the Regional Council of the Cohesion Region South-East was established and it took over the part of district competences. The South-Moravian Tourist Authority (CCRJM) is an executive and partially also marketing organization. It was founded in 2006 just for the purpose of performing destination management in the district. The founder members of this association are the South-Moravian region, the statutory city of Brno and the Czech Confederation of Commerce and Tourism (SOCR).

Furthermore, local tourism organizations are active on the lower hierarchy level in JMK, for instance, in the area of Slovácko or the Moravian Karst. For the city of Brno and its surroundings, this destination management function is carried out by the Brno City Municipality and the Brno Tourist Information Centre. JMK is divided into five natural tourist regions, but not even in the half of them, there are organizations of destination management working actively and their activities are insufficiently replaced by tourist information centres in many cases.

A survey among travel agencies and offices dealing with domestic and incoming tourism has been conducted for the purpose of finding out the level of functioning partnerships in JMK. The survey was conducted in the form of a combination of internet and telephone investigations. The final number of subjects that participated in the survey is 29. The database of the Association of Travel Agencies was used when looking for suitable subjects that would fulfil the survey criteria. The size of travel agencies and offices did not play any part in the selection, what was crucial was the orientation of their activities.

$50 \%$ of the addressed companies were aware of the existence of CCRJM. In some cases, the question concerning the existence of CCRJM was completely new information for the subjects. More than half of the addressed companies are not planning to start cooperating with CCRJM, which gives the evidence about their very weak positions and images in JMK so far.

Regarding the fact that CCRJM has only been active on the tourism market for a year and a half, we cannot expect it to be generally well-known among all other interested subjects or even in the general public.

The depth interview with the project manager of the central office shows that CCRJM contacts their potential partners itself and directly offers them to cooperate. However, the conducted survey did not prove this fact very much as only $10 \%$ subjects mentioned that the centre office had addressed them and asked them for cooperation. The survey did not confirm any link between the size of addressed subjects and their cooperation with CCRJM.

The partner travel agencies' statements say that the cooperation with CCRJM lies on taking part in workshops, opportunities to present their materials at fair-trades or including products in promotion materials or websites of the central office.

Other points at issue that were a part of the survey concerned using the logo of CCRJM and the unity of the 
destination image. None of the addressed agencies or offices uses the logo of CCRJM either in their printed materials or on their web pages. Only one travel agency stated that they use references of the JMK official tourist web portal for their presentations. The subjects only use their own marks and labels supplemented with the logo of ACK if they are members of this association. So in this area, there is also a challenge for CCRJM and JMK concerning finding a suitable marketing logo that could be used by all key partners for reflecting themselves.

We can state that in the area of JMK, there has not been a unified organization structure of tourism so far as it can be seen for example, in Austria or Croatia, where a pyramid system has been created, starting from central marketing organization up to even the smallest units.

\section{Conclusion}

The paper outlined the main theoretical basis, principles and tools of destination management and subsequently, it summarized the results of the analysis and conducted survey, the objective of which was to prove the functioning of these principles in practice, namely in JMK.

Based on the literature available, conception documents and conducted surveys the main problems in JMK seem to be lying on the following:

- Insufficient cooperation of public, business and non-profit sectors: The absence of functioning cooperation is a brake for the development of tourism and prosperity. There can be more reasons for this fact. Entrepreneurs are not interested in cooperation, as they believe that their individual activities will bring them enough profit; On the other hand, the public sector is unable to motivate them enough and to persuade them to cooperate, which cannot explain the benefits of this from the point of view of higher profits emerging from such partnership, creating a good name and reputation, and it is unable to convince them about the necessity of further development. The rate of mutual organization and coordination of activities in the frame of public-private partnership can be labelled as low. Mutual trust of individual subjects seems to be a large drawback. It seems necessary to create links of trust, so that one businessman could rely on another one in the framework of their activity. Nevertheless, it will not be easy in the Czech environment at all.

- Superiority of tourism regional authorities: Tourism regional authorities as well as destination management companies in individual areas of JMK cooperate with entrepreneurs rarely or not at all. This has fatal consequences especially for creating conceptions. Then, these create a chaotic mosaic with no unifying element. Such an isolated preparation of projects on both sides is a proof of why especially private subjects do not cooperate sufficiently and are not aware of the necessity of further development in the branch of tourism.

- Inconsistent presentation: JMK has its own web portal of tourism with markers of individual natural tourist regions in the district. The drawback lies on the absence of references to these regions' websites where tourist can be offered more possibilities and up-to-date information. At the same time, these individual areas are presented on other tourism servers in a different way, with different information and different aging. Such non-systematicness can give tourists a misleading impression of an inconsistent region that has a fragmented and non-complex offer of services. And what is more, they can be rather confused by different information from different sources and so they might not orient themselves well in the region.

- Insufficient qualifications: Tourism services of a good quality cannot be ensured on the required level if they are provided by non-qualified workers without the ability to speak foreign languages. The unwillingness to learn 
more and improve oneself is much stronger than the awareness of such benefits for the development of tourism. Well-qualified and educated people often leave the region. JMK and CCRJM try to organize a lot of trainings and seminars. However, the above mentioned problem seems to appear here again-The organizers of these programmes are not able to persuade small entrepreneurs and service providers about the importance of education for the development of tourism.

- Insufficient tourist infrastructure: It is a given fact that the development of tourism is closely connected with the quality of tourist infrastructure and complementary services. The consequence of the imperfect structure of tourism management, insufficient political preferences and so the lacks of financial means for the development of tourism appear in this area as well. JMK as a tourist destination is competitive only in Brno when compared with EU standards and foreign tourists' requirements. Other areas in the region are rather backward and it is inevitable to invest in the tourist infrastructure quite a lot.

- Little knowledge about the possibilities of financing from EU sources: Regarding the low level of cooperation, businessmen, especially those smaller subjects in more outlying areas of the district and in the country, have rather little knowledge about the possibility to use financial means from European sources.

\section{References:}

Bartl, H. \& Schmidt, F.. (1998). Destination management. Institut für regionale Innovation, Wien.

Bernátová, M. \& Vaňová, A.. (2000). Marketing for authorities. Banská Bystrica: Ekonomická fakulta UMB, 2000, 180s.

Buhalis, D.. (2000). Marketing the competitive destination of the future. Tourism Management, 21(1), 97-116.

Hesková, M., et al.. (2006). Tourism (1st ed.). Praha: Fortuna, 224.

Királ'ová, A.. (2004). Marketing of tourism destination. Praha: Ekopress.

Palatková, M.. (2006). Marketing strategy of tourism destination. Praha: Grada Publishing.

Ryglová, K.. ( 2008). Destination management. Agricultural Economics, 9(54), 45-53.

(Edited by Ruby and Chris) 